\title{
CONSIDERACIONES SOBRE EL EXAMEN DE LAS MUESTRAS PROVENIENTES DE LA PERFORACION DE POZOS (*)
}

CARLOS CASTILLO TEJERO (**)

Los trabajos de geología de subsuelo se pueden dividir en dos grupos principales, trabajos de campo y trabajos de gabinete. Ambos tipos de trabajo son igualmente importantes y están relacionados intimamente, pudiendo de hecho decirse que la calidad y veracidad de los resultados del trabajo de gabinete están supeditados a la calidad y comtidad de datos obtenidos en el campo.

Uno de los trabajos más importantes que se llevan a cabo en geología de subsuelo, si no el más importante, es el estudio de los cortes provenientes de la perforación de pozos.

El geólogo de pozo, al llevar a cabo el examen de las muestras debe considerar, preferentemente, que los datos obtenidos servirán para resolver muchos problemas tanto particulares del pozo, como locales o regionales y por consiguien te que la informacion que debe obtener, para tener utilidad, deberá ser abundante $\mathrm{y}$ sobre todo, probada.

El estudio de los cortes provenientes de la perforación de pozos petroleros tiene tres aspectos fundamentales:

a) Determinar los contactos entre las dfferentes formaciones del subsuelo.

b) Interpretar la estratigrafía local para utilizarla en problemas de estructura regional y local, sedimentación $y$, en su caso, acumulación de hidrocarburos.

c) Investigar el carácter económico de los horizontes para poder aplicar, en su caso, los métodos de producción adecuados.

Tanto el carḱteter litológico de una muestra como las relaciones que guardan entre sil diferentes muestras de un mismo pozo se pueden determinar por el estudio adecuado de los

(*) Original recibido en enero de 1955

(**) Secretario de la Escuela Nacional de Ingeniería (Palacio de Minería) 
diferentes fragmentos cortados por la barrena, a simple vista, con ayuda del lente de mano o bien de un miscroscopio para litologia.

Como sabemos, las muestras provenientes de las perforaciones son de dos tipos: de canal y de núcleo. Las primeras son recogidas en la superficie mediante el sistema de circulación del lodo, a intervaios que varion según el tipo del pozo, (de exploración o de explotación) y que pueden variar desde un metro (conveniente para pozos de exploración) hasta 10620 metros (para algunos pozos de explotación en campos conocidos). El intervalo de muestreo está relacionado con la aproximación que se desé para obtener la información adecuada al objeto de la investigación; por ejemplo, el grado de conocimiento de los contactos, las características particulares de los diferentes estratos, etc).

La determinación de un contacto puede requerir que el muestreo se haga a intervalos de un metro o aún menores en los casos de los horizontes productores, pero claro es que no será el caso general. Sin embargo, es recomendable hacerlo para aquéllos pozos de exploración que sirven para investigar la secuencia estratigráfica. En otras palabras, debe procederse $\alpha$ un muestreo continuo o bien a intervalos muy cercanos uno de otro y una vez que la secuencia de las capas ha sido establecida, puede ampliarse ese intervalo dejando el asunto al criterio del geólogo que se encargue de los traba. jos de subsuelo de esa ́ŕrea.

Sin duda, el mejor método para conocer las condiciones reales del subsuelo es el de obtener muestras con saca-núcleos pero como por regla general este procedimiento es bastante costoso, se trata de evitar en lo posible hacer tal muestreo, y se) realiza solamente en forma esportadica, y, ésto cuando los estudios de las muestras de canal indican la conveniencia de hacerlo.

Las muestras de canal provenientes de la perforación con equipo rotatorio no proporcionan información precisa por el grado de contaminación causado por la recirculación del material de la formación. Este factor ocasiona que los contac- 
tos de las formaciones, tanto desde el punto de vista litológico, como paleontológico, sean difíciles de precisarse con la debida aproximación, salvo en aquellos casos en que se tengan conocimientos previos de la columna geológica que se está atravezando. Las muestras provenientes de perforaciones hechas con pulseta, en lo general permiten un mejor resultado desde el punto de vista de información geológica, pues con este método la contaminación de muestras es minima, sin embargo este procedimiento de perioración para pozos petroleros es prácticamente obsoleto.

Antes de iniciar el estudio de una muestra, debe tenerse la precaución de limpiarla perfectamente, para lo cual es necesario remover tanto los restos del fluído de perforación como el polvo que se hubiere acumulado; no tener esta precaución puede producir un confusión al determinar el carácter litológico de la muestra; por ejemplo, un fragmento de arenisca de grano fino cubierto por lodo de perforación, puede ser confundido fácilmente con una lutita o una limalita( siltstone).

Un procedimiento usual que permite estudiar las muestras desde un mismo punto de vista es el llamado "Método Húmedo", el cual consiste en examinar los ejemplares (previamente limpios) sumergidos en agua, lo cual hace más notables algunas de las características de la roca y por consiguiente mós faciles de precisor.

Para estimar el valor de las muestras procedentes de los pozos es necesario considerar varios factores: calidad y cantidad de la muestra, continuidad del muestreo e intervalo de obtención. Además de estos factores debe tenerse muy en cuenta la ecuación de los factores humanos, factores que tienen importancia en la realización del trabajo. La experiencia nos indica que la responsabilidad de la persona que colecta las muestras es trascendente; un mal muestreo causado por descuido del personal 0 un falso muestreo ocasionan multitud de problemas de interpretación antes de que se verifique la falsedad de la información. 
Los cambios de formación sugeridos por las muestras pueden ser mejor valorizados cuando simultáneamente con el estudio geológico se utilicen los varios tipos de registros de pozos (eléctrico, radiactivo, velocidad de perforación, etc.).

Considerando que para interpretar correctamente la columna cortada por un pozo deben utilizarse todos los datos disponibles, se debe insistir en señalar la importancia de coordinar en forma adecuada los datos obtenidos de los estudios mineralógico, litológico y paleontológico, además de los datos obtenidos de los diferentes registros mecánicos. El exceso de confianza sobre un tipo de información, por lo general conduce a interpretaciones erróneas que consecuentemente repercuten en los intereses económicos. A propósito de lo anterior, hay profesionistas que consideran los registros eléctricos como el resultado inapelable para la interpretación de la sección de un pozo. Sin negar la gran ayuda que representan, rara vez se logra saber si el registro se obtuvo con positivo éxito o cúal era el grado de densidad del fluído de perforación, o bien si se anotaron correctamente las variaciones en las características de las formaciones. Debe recordarse que el registro eléctrico ofrece datos díficiles de interpretar en una forma correcta si no existe la ayuda de otro tipo de registro y del muestreo litológico del pozo.

Para darse cuenta de los cambios litológicos que se pre. sentan en un segmento de la columna geológica de un pozo petrolero, puede recomendarse el método siguiente:

1) Tomar $15 \circ 20$ muestras consecutivas y arreglarlas sobre una mesa por orden de profundidad, observando el conjunto para darse cuenta de la existencia de algún cambio litológico importonte (aparente al menos).

2) Examinar cada muestra ya sea a simple vista, con la lente de mano o si es necesario utilizando un microscopio para litología, para anotar con la mayor precisión posible las características más importantes de la muestra. No es necesario, salvo en casos especiales, el examen de toda la muestra, pero si lo es, el determinar el aspecto representativo de la roca. 
3) Elaborar un geograma o corte litológico, usando indistintamente colores o símbolos para indicar la litología de las muestras, sin olvidar nunca el registro, breve pero conciso de las descripciones generalizadas de muestras con canacterísticas semejantes, de los cambios litológicos importantes $\mathrm{y}$, de ser posible, sus edades. En las descripciones deben abreviarse los diferentes términos, pero sin confusión. Además, cuando las muestras sean fosilfferas, deberá indicarse con el símbolo respectivo, lo mismo cuando se encuentren impregnadas de hidrocarburos.

Cuando se esperan cambios de formación, es necesario un cuidado especial en las proximidades de dichos cambios. Oca. sionalmente se impone la necesidad de reestudiar las mues. tras, cuando un contacto no ha podido ser identificado. Hay ocasiones en que el cambio litológico es gradual y no se percibe que se está en otra formación hasta después de 15 o 20 metros de la zona de contacto.

Considerando que las muestras de conal representan generalmente una mezcla de material de diversa índole, resulta muy conveniente para aquellos profesionistas no familiarizados con la columna geológica de cierta región, consignar en el geograma en forma gráfica los porcentajes de los diversos materiales encontrados en cada muestra.

Resulta práctico utilizar 10 divisiones para representar cada una un $10 \%$ del total de la muestra e indicar con colcr azul la caliza, con amarillo la arena y dejar sin colorear lo correspondiente a lutita; otros materiales deben señalarse de acuerdo con la gama de colores de que se disponga o utilizando los símbolos convencionales. Dicho procedimiento presenta una gran ventaja en aquellos casos donde los sedimen tos que se pertoran son de tipo transicional, en los cuales el nombre varia de acuerdo con la persona que lleva a cabo el estudio. Así por ejemplo, lo que un geólogo podría llamar lutita calcárea, podría ser considerado por otro como una marga y por otro más como una caliza arcillosa. 
Para utilizar mejor los datos obtenidos de los cortes y tener una mayor comprensión del significado de los registros litológicos, se puede recomendar obtener de las muestras, cuando se trate de material sedimentario, los datos que se indican a continuación:

a) Sedimentos de grano medio a grueso (conglomerados $y$ areman)

Color (uniforme, abigarrado, bandeado u otras variaciones).

Textura (gramo fino, medio o grueso)

Estructura (masivo, laminar, trenzado)

Grado de coherencia o de fragilidad (resistente, quebradizo).

Cardcter y tipo del cementontel calcúreo, sillicoso, ferruginoso, arcilloso).

Minerales primarios y crcesorios (cuarzo, feldespato, pirita, glauconita, ferromagnesianos, magnetita)

Carácter de los granos (esfericidad, superficie, cristalinidad, caras secundariors, caracter de alteración) Clasificación de los granos (uniforme, mezclado) Grado de pureza del material (arcilloso, limosos, calcóreo)

Tamaño de los gromos (Para fines prácticos, pueden considerarse como sigue: arena muy gruesa l-2 mm.; arena gruesa 1-1/2 mm.; arena medila 1/2-1/4 mm.; arena fina 1/4-1/8 mm.; arena muy fina 1/8-1/16 mm.; limos: 1/16-1/256 mm.; creilla: <l/256 mm.).

b) Sedimentos de grano fino (arcillas, limos).

Para describir a los sedimentos de grano fino se usan diferentes términos de los cuales indicaremos los más usuales:

Iutita. -Sedimento laminar, endurecido o quebradizo compresto de material fincmente dividido del tomaño clasificación y composición de la arcilla. 
Iodolita-(lodo endurecido).-Sedimento endurecido. masivo, nunca laminado, compuesto por material del tamono, clasificactión y composición de la arcilla.

Argilita-Material finamente dividido, generalmente masivo, con considerable plasticidad cuando húmedo. Las variedades bien consolidadas pueden confundirse con lodolita.

Limolita-Matertal arenoso consolidado, de grano muy fino, cuyas partículas son del tamaño del limo (1/16-1/256 mm.). Pertenece $\alpha$ un grupo transicional entre sedimentos arenosos y arcillosos.

Cuando se examina los sedimentos arcillosos se recomienda anotar las siguientes características:

Color (uniforme, bandeado, abigarrado, jaspeado, multicolor).

Estructura (masivo, laminar, quebradizo).

Carácter (arcilloso, arenoso, limoso).

Minerales accesorios (pirita, glauconita, mica, etc.). Los minerales accesorios pueden servir para calificar al material bajo descripción, ej. miớceo, glauconítico, etc.

Contenido de fósiles (abundante, poco).

\section{c) Sedimentos calcórreos.}

Los sedimentos calcáreos más importantes son las calizas y las dolomitas. Cuando se examinan sedimentos de este tipo se recomienda anotar las siguientes características:

Color.

Cristalinidad (fino, medio,-grueso, denso).

Estructura (masiva, carvernosa, en capas, oolítica, pisolitica).

Minerales accesarios (sílice, pirita, glauconita, pedernal). 
Impurezas (arcilla, arena).

Porosidad (alta, regular, baja).

Contenido de fósiles.

Recristalización.

Fracturamiento. 